\title{
Relationship of Target-Based Orientation and Competitive Anxiety With Female Basketball Players' Performance
}

\author{
Gul Eda Burmaoglu \\ Correspondence: Gul Eda Burmaoglu, Faculty of Education Sciences, Ataturk University, Erzurum, Turkey.
}

Received: August 20, 2018

doi:10.11114/jets.v6i9a.3571
Online Published: August 27, 2018

Accepted: August 24, $2018 \quad$ Online Published:
URL: https://doi.org/10.11114/jets.v6i9a.3571

\begin{abstract}
The main purpose of this research was to determine relationship of the target-based orientation and the Competitive anxiety with the young Basketball players' performance in Erzurum province championship tournaments. So the whole young Basketball players' of Erzurum Province participating in the championship tournaments in 2014 were selected as the statistical technique. The questionnaire of the target-based orientation at sport and the questionnaire of the competitive anxiety and the study of the Basketball players" results were applied in order to gather the related data. This study was an applied and a descriptive-correlation type. The results showed there is a significant relationship between the target-based orientation and sport performance of Basketball players' participated in Erzurum championship tournaments. There is also significant relationship between the task-based element and sport performance of the young Basketball players'. There is no observed a significant relationship between the target-based orientation and sport performance of the Basketball players'. There is a significant relationship between the competitive anxiety and the sport performance of the young Basketball players' in the championship tournaments of Erzurum.
\end{abstract}

Keywords: orientation, competitive anxiety, basketball

\section{Introduction}

There are various studies about sport psychology and most of them represent the effect of motivational aspects of human behavior particularly to sport science. The investigation of different dimensions of motivational issues such as competitive anxiety and personal traits can give some new results and findings all about the athletes' spiritual behaviors and moods. The championship sport can increase social emotional and life hope. The acquaintance of health and reduction or prevention of diseases is main purposes of sport (Arsalan, 2009). The highest degree of anxiety often leads to weak performance of all athletes; for the reason, all athletes require to pay special attention to this issue. Hence, a sport coach or sport psychologist's task is to assist an athlete to tolerate all anxiety conditions in order to reach to better performance because this reduces the anxiety levels of all athletes in this regard. Along with the physical readiness, the spiritual readiness should be roughly paid attention potentially (Arsalan, 2009). The main aim of competitive anxiety is subjected to the anxiety mood and competitive trait of an athlete. According to Speilberger (1996) the mood anxiety is subjected to an emotional and transient reaction leading people to evaluate the different threatening situations. In contrast, the anxiety trait is subjected to the personality trait that it points to traits with stable personal traits and differences among people susceptible to the anxiety. The results emphasize on the relationship between the anxiety and performance representing the negative effect of anxiety on all athletes' performance (Arsalan, 2009). The competitive anxiety can also effect on performance of all athletes itself. Another important variable influencing on the sport performance is subjected to target-based orientation. Generally, individuals have their own self orientation or self-task issues regarding to related duties (Coknaz, 2016). The results of present study showed that athletes being fluent on sport atmosphere receive the highest internal motivation having positive attitude towards sport and applying the most fluent purposes and information for evaluating of their own performance. As a result, they can also raise their self-efficacy beliefs and feeling that sport activities are very positive for challenging. In contrast, when these athletes have negative attitudes towards their sport environment, they will consider the same environment as the fighting atmosphere indicating the negative perceptions and having low self-efficacy and using abnormal information about their purposes; they will also focus on the results of the activities (Davut, 2009). Ryan (2001) has defined the self- orientation as ability to choose the most determinant factors regarding their personal issues. When these individuals are getting to be considered as determinant, they will consider the self as the beginner of their own behaviors. On the other hand, a person having the task-based criterion along with self -orientation reward system can also change into the 
other-independence. The task-based people are those who have job orientation and they can get rid of all related norms focusing merely on potential group success.

When someone feels that he or she is able, he will admit the responsibility of all sport events and results personally. In other words, he or she will be motivated for these activities and events. People allocating the sport orientations are challenging in the physical sport events and activities for various reason in different situations (Ersoz, 2015). Hence, the consciousness of these events why people have the highest motivation for reaching to these purposes is very important for many people in this field. Wrestling is one of the oldest sports of the world dating back to the pre-history era that has been constructed by the change of the face-to-face challenges and wars during the history. Due to the nature of the related sport, the anxiety and the spiritual moods of an athlete can influence on the performance of an athlete and his or her results. The personality aspects (task orientation and self- orientation) can also play a key role in wresters' sport performance. Many athletes having the highest readiness could not indicate their performance over the related tournaments (Arsalan, 2009). The researcher is looking for of these questions to determine whether there is any relationship between the elements of the task-based orientation and the performance of the related Basketball players', there is any relationship between the competitive anxiety and performance of young Basketball players', these are target-based orientation elements and competitive anxiety considered as predictors of young Basketball players' performance of Erzurum championship tournaments. Due to the mentioned questions, the author tried to determine relationship between the competitive anxiety and target-based orientation with young Basketball players" performance participated in Erzurum championship tournaments in present study because this obtains some useful information and assist all officials and coaches regarding to the personality aspects of athletes' anxiety. As Omit (2014) study showed there was significant relationship between feeling of usefulness of wrestling skills, the results of the completion and the competitive anxiety. In a study done by Coknaz (2016) we see that the highest mean of the cognitive and physical anxiety factor is subjected to chess players and the lowest degree is related to the Basketball players. The highest mean of the self-confidence factor is subjected to the volleyball players and the lowest degree is related to the chess players. In addition, the highest mean of competitive anxiety is subjected to chess players and the lowest degree is related to Basketball players. Also, Gullu (2013) in her research showed that the competitive anxiety of group and individual sport fields is different together and the individual sport fields are more anxious than the team ones. We see that Ruzgar (2012) evaluated relationship between target-based orientation and the seventh resources of self- confidence of Basketball players' concluded that about $87 \%$ of basketball players' tend to have task-based orientation in their sport affairs. Omit (2014) showed that every intriguing variable has negative relationship with the competitive anxiety and the sport performance and the educational progression. This correlation is higher among the group athletes in compare to individuals. Sekaran (2016) showed that there is a significant relationship between the overcoming approaches and the group sport athletes. Temel (2012) showed that when the competitive anxiety is increased among Talo Players, the competitive performance will be decreased, too. Arsalan (2009) showed that there is a positive significant relationship between the competitive anxiety and self- orientation among male stone-climbers. Taibolt (2010) showed that there is a significant difference between the competitive anxiety (physical signs, mental and self- confidence) regarding to female football players and college female players. Also, there is a direct relationship between the competitive anxiety and performance of all female football players.

\section{Methods}

This study is a descriptive-correlation and applied study; it is also tried to determine the target-based orientation and competitive anxiety of basketball players' along with sport performance in this study.

\subsection{Population and Statistical Sample:}

The statistical population of this study is subjected to whole young Basketball players' of Erzurum Province participating in championship tournaments in 2016. The statistical sample is selected as all-counting case due to the volume of the same population $(\mathrm{N}=\mathrm{n}=150)$.

\subsection{Tool and Measuring Method}

The questionnaire of target-based orientation at sport and questionnaire of competitive anxiety and study of Basketball players" results are applied in order to gather related data as following:

1- The target-based orientation at sport questionnaire (TEOSQ): this includes 13 questions regarding to the target-based orientation (TEOSQ) led by Duda and Nicolls in 1992 in order to measure the target orientation at sport environment having two scales regarding to task and self being applied to specify this process (Arsalan, 2009). This defines someone's sport success and situation in order to gain the highest skill (task-based coordination) along with raising the performance in compare to others 
2- The competitive anxiety questionnaire (SCAT): this questionnaire has been led by Martins, Willy and Barton in 1990 (Arsalan, 2009); this determines degree of competitive anxiety among all athletes. This questionnaire includes 15 questions and every question has three choices as "rarely", "sometimes" and "often" representing athlete's feeling about same questions.

\subsection{Reliability and Validity of the Questionnaires}

The 13-questions questionnaire is established to the target-based orientation (TEOSQ) and the 15-questions questionnaire is to determine the competitive anxiety (SCAT) and recent reliability and validity of these questionnaires have been confirmed as standard in this study. Due to context of questions, completion ability of questionnaires is different country to country.

\subsection{Validity}

The 13-questions questionnaire is established to target-based orientation (TEOSQ) and 15-questions questionnaire is to determine competitive anxiety (SCAT) and recent reliability and validity of these questionnaires have been confirmed as standard. The Cronbach alpha coefficient of task-based and self-based orientations is reported 0.80 and 0.78 , respectively. The validity of these questionnaires is also measured after gathering Cronbach alpha coefficient in this present study that target-based orientation is measured 0.78 and competitive anxiety is calculated 0.83 in this case.

\subsection{Data Gathering Method}

The related questionnaires are held in Erzurum after the related coordination with the province basketball board and tournaments officials' permission in order to gather the related data. These have been also distributed among basketball players' and then all questionnaires were returned completely. The necessary explanations have been completely achieved before distributing the questions because this makes all participants aware of the purposes and targets of the related questionnaires. The target-based orientation questionnaire is distributed and gathered only one day before the beginning of the tournaments. The competitive anxiety questionnaire is subjected to half or one hour before the beginning of the tournaments and all participants are let respond the questions. In the end of the tournaments, by the coordination of the wrestling officials' agreement, the results of the tournaments and the records are also registered and the status of the Basketball players' is also registered in this case.

\subsection{Statistical Analysis Method}

The obtained data of study have been estimated by the use of statistical methods; the correlation coefficient between the independent and dependent variables are subjected to two-values type of performance variable along with the normal fundamental distribution (success and unsuccessful) and the competitive anxiety and sport orientation are multi-values type of variables. The correlation test statistical technique is also applied in this study. Logistic regression analysis is also applied to predict the sport performance.

\section{Results}

Table 1. Two points filed correlation test

\begin{tabular}{lllll}
\hline Variables statistical indexes & Correlation coefficient (ETA) & $\mathrm{R}^{2}$ & \multicolumn{2}{l}{ Sig. } \\
\cline { 3 - 5 } & & 0.025 & 0.45 & Pearson approximation \\
\hline Orientation and performance & $0.19^{*}$ & 0.032 & 0.01 & 0.02 \\
\hline Task-based and performance & $0.18^{*}$ & 0.002 & 0.56 & 0.02 \\
\hline Self-based and performance & 0.07 & 0.069 & 0.001 & 0.35 \\
\hline Competitive anxiety and performance & $-0.24^{*}$ & 0.000 & \\
\hline
\end{tabular}

Based on the information of table 1, there is a significant relationship between the target-based orientation and sport performance of basketball players' participated in Erzurum championship tournaments. There is also significant relationship between the task-based element and sport performance of the young basketball players'. There is no significant relationship between the self-based orientation and sport performance of basketball players'. There is a significant relationship between the competitive anxiety and the sport performance of the young basketball players' in the championship tournaments of Erzurum.

\section{Discussion}

If it is assumed that there is a significant positive relationship between the target-based orientation and the sport performance, it will be confirmed that it is coincident with the results of Kandaz (2012), Manzini (2016) and Omit (2014). Although these studies are different with our studies in terms of subjects' viewpoints but results are lines with this study purposefully. These researchers have pointed to the role of target-based orientation in the sport performance. Since the correlation of the target-based orientation with the sport performance is an outstanding case among athletes, it can be claimed that the personal differences can determine the results of the athletes' performance in relation to task-based orientation or self-based orientation affairs. According to the results of the present study, it can be stated that 
the task-based orientation can create much satisfaction for athletes leading to have better performance during the tournaments. Based on the results of the present study, most Basketball players' tend to apply the task-based on trying to optimize their own skills potentially. Ruzgar (2012) in a study concluded that about $87 \%$ of Basketball players' tend to have task-based orientation that it is coincident with the results of the present study. But in this relation, this is not adaptive with the results of Manzini (2016) because he showed that Asian players have lower level regarding to the task-based orientation and they are only better in having the self-based orientation issues. The main reason of this distinction is subjected to the different levels of the target-based orientation. For the reason, the complementary evaluations along with the related conditions can come along with accurate response in this regard. Sekaran (2016) has shown that there is a significant relationship between the overcoming approaches and the target-based orientation issues and the sport performance. Manzini (2013) argues that people with high task-based orientation have higher self-confidence, better social support and fluent skills; they consider only success as their main factor for constructing their self- confidence issue. Thaing et al (2013) in a longitudinal study on students obtained the highest relationship between target-based orientation learning and determination of purpose and performance. Increase or decrease of self-based orientation of basketball players' does not have any changes on sport performance. This result is line with results of Kandaz (2012), Manzini (2013), Temel (2012). These researchers did not find any significant relationship between self-based orientation and sport performance, it is shown that players getting higher scores in competitions have little anxiety, better and satisfying performance in tournament situations. It seems that the personal differences could be the main reason for these distinctions between the results. Finally, if it is assumed that there is a negative relationship between competitive anxiety and sport performance. It is line with result of Sekaran (2016), Taibolt (2010). These researchers have shown that the highest competitive anxiety can reduce success of all athletes during tournaments. Based on this pattern, the limitation of the optimization performance of every athlete should be exclusively established trying to raise his or her performance. In other words, every athlete has his or her own better performance in a special territory of the anxiety. On the other hand, when these athletes get out of their own territory or limitations, they will have weakened performance in this pavement. Sekaran (2016) discovered negative significant relationship between competitive anxiety and the sport performance among the group-based athletes. Also, the strongest predictor is subjected to the target-based orientation among the individual athletes and the target-based and competitive anxiety is subjected to group-based sport athletes. Temel (2012) has also obtained similar results in this regard. The results of Manzini (2016) revealed that there is a direct relationship between the competitive anxiety and performance of female football players. Davut (2009) investigated competitive anxiety among skilled wrestlers in USA and showed that wrestlers with low SCAT had better ability in compare to high SCAT wrestlers and they also predicted that they might get successful results. The results of Kandaz (2014) showed there is relationship between mental indexes (POMS) and tournament anxiety (SCAT) with sport performance; it is shown that athletes with highest SCAT in beginning of league have highest tiredness before and during tournaments and lose the matches. Hanton et al (2004) obtained negative relationship between competitive anxiety and sport performance. But along this, Gullu (2013) in a study could not find any significant relationship between competitive anxiety and sport performance among tennis players. It seems that application of accurate tool or lack of any suitable response of subjects has not been led to specify better changes in this pavement.

\section{References}

Arsalan, M. (2009): the relationship between the organizational structure and managers' creation of the physical training organization, a thesis for MA, physical training faculty of Gazi university.

Coknaz, P. (2016). Research methods in social sciences, Ankara, institute of research and education of management.

Davut, M. (2009). The investigation of the football federation organizational structure, Tehran, publication of the management and planning institution, $2^{\text {nd }}$ printing

Ersoz, H. (2015). The determination of the relationship between the organizational structure with staffs tolerance against any changes in Tehran municipality Education organization, a thesis for MA, physical training faculty of

Gullu, A. (2013). The analysis and investigation of the Garanti Bank organizational structure and an optimized given pattern, a thesis for MA, management faculty of Karadeniz University.

Kandaz, D. (2014). Comparison of the Turkish physical training organizational structure and some other countries to represent a suitable pattern, a thesis for MA, physical training faculty of Adiyaman University

Manzini, A. (2013). The analysis and investigation of the Garanti Bank organizational structure and an optimized given pattern, a thesis for MA, management faculty of Karadeniz University.

Manzini, A. (2016). Organizational pathology, publication of Dogan, Turkey.

Omit, A. (2014): the relationship between the organizational structure and managers' creation of the physical training 
organization, a thesis for MA, physical training faculty of Inion University.

Ruzgar, M. (2012). The determination of the relationship between the organizational structure (complexity, formality and concentration) with the partnership management of the physical training experts, a thesis for MA, physical training faculty of Mersin University.

Sekaran, O. (2016). Research methods in management, publication of the management and planning institution, Ankara. Selcuk University

Taibolt, L. (2010). The organizational changes in the Canada Education system, a thesis for MA, physical training faculty of Karadeniz University.

Temel, A. (2012). Organization and management, Trabzon, Molavi Publication.

\section{Copyrights}

Copyright for this article is retained by the author(s), with first publication rights granted to the journal.

This is an open-access article distributed under the terms and conditions of the Creative Commons Attribution license which permits unrestricted use, distribution, and reproduction in any medium, provided the original work is properly cited. 